\title{
Phytosynthesis and Characterization of Silver Nanoparticles Using Leaf Extracts of Premna Serratiffolia L
}

Soumya Soman, Joseph Ray*

Mahatma Gandhi University, School of Biosciences, Kerala 686560 India

* Corresponding author: J. Ray (methikalamray@yahoo.com)

\begin{abstract}
Biosynthesis of nanoparticles using plants and microbes reduce toxicity and enhance biocompatibility of the particles produced. Phytosynthesis makes use of the principle of reduction of metal ions in aquous extracts of plant leaves that may lead to development of nanoparticles. Therefore, production of silver nanoparticles was experimentally tried out using leaf broth of Premna serratifolia L in accordance with standard procedures. The UV-vis spectra gave an SPR band at $422 \mathrm{~nm}$ and TEM analysis revealed the formation of nanoparticles in the range of 3-12 nm. The XRD studies showed that particles are crystalline with face centered cube geometry. The reduction and stabilization of the ions are attributed to the hydroxyl and amine groups present in the leaf broth. This method of synthesis of silver nanoparticles has the potential to become an alternative eco-friendly method of synthesis.
\end{abstract}

Keywords: Phytosynthesis, Leaf extract, Phytocompounds, Silver nanoparticles

Citation: S. Soman and J. Ray. Phytosynthesis and Characterization of silver nanoparticles using leaf extracts of Premna serratiffolia L Nano Biomed. Eng. 2011, 5(4), 155-159. DOI: $10.5101 /$ nbe.v5i4.p155-159.

\section{Introduction}

Nano-biotechnology makes use of nanosized metal particles to have tremendous impact in various medical applications in gene delivery [1-3], in X-Ray imaging [4] and also in nano sensing devices [5]. Physical, chemical and biological methods [6-8] are used to synthesize nanoparticles. Physical and chemical methods are the classic methods, but they are not environment friendly. Harsh solvents or surfactants used in such synthesis generate hazardous waste and uncontrolled release of nanoparticles into environment causing unpredictable consequences to human health and natural biodiversity $[9,10]$. Therefore, the options of alternative synthesis are seriously experimented. Recently, biosynthesis using plants and microbes is emerging as an eco-friendly method of nanoparticle production.

Biosynthesis is a bottom up approach employing biological organisms or materials for the formation of nanoparticles. Prokaryotic bacteria, actinomycetes and eukaryotic plants are used in reducing metal ions in aquous solutions to metal nanoparticles. Increased tolerance to metals in plants may be an indication of the ability of plant-parts for biosynthesis of nanoparticles [11]. Biosynthesized nanoparticles have many advantages over that of chemically and physically synthesized particles. They are more biocompatible [12] and the synthesis is a single-step protocol [13]. Notable progress has been recorded in phytosynthesis of nanoparticles with controlled size and shape. Several attempts in the synthesis of nanoparticles using plant materials such as leaves [14], fruit [15], latex [16] and bark [17] of diverse species are reported. Shankar et al [12] observed that nanoparticles synthesized using plant extracts are stable even after 4-5 weeks of synthesis, attributed the same to diverse kinds of biochemicals present in such plant materials.

Among the various nanoparticles, silver nanoparticles have unique applications in diagnostics as biological tags for quantitative detection; and the particles also have conductive and optical applications [18]. Silver particles have antibacterial properties [19] and are used in healthcare and fabrics [20,21]. Plant community is so diverse such that the potential of different plants for synthesis of nanoparticles need to be fully explored. Premna serratifolia L, commonly known as headachetree is a well-known medicinal plant, an ingredient of the famous Ayurvedic 'dasamola'. The antioxidant properties and tumor cell suppression activities of Premna serratifolia L have been reported [22]. Phytochemicals involved in such properties can not only support and speed up nanoparticle formation, but also can improve biocompatibility of the synthesized nano particles. Therefore, synthesis of silver nanoparticles using the leaf extract of Premna serratifolia L is experimentally tested to examine its potential in nanoparticle synthesis. Synthesis of silver nanoparticles of 3-12 nm and relatively high stability is the success of this attempt. 


\section{EXPERIMENTAL DETAILS}

\subsection{Plant material and Extract preparation}

Premna serratifolia $\mathrm{L}$ is from the family Verbenaceae. Fresh leaves were collected from Kasargod District of Kerala State. About $10 \mathrm{~g}$ of the fresh leaves were initially surface cleaned with the detergent Tween 20 , then in running tap water and finally in ultrapure water . Leaves were cut into small pieces and the chopped leaves were boiled in $75 \mathrm{~mL}$ ultrapure water for $5 \mathrm{mts}$ in a $500 \mathrm{~mL}$ Erlenmeyer flask. The plant extract obtained was allowed to cool. It was then decanted and filtered using Whatmann No.1 paper. The color of the broth was noted and stored in refrigerator at $4^{\circ} \mathrm{C}$ for future use. The plant extract was used within seven days for synthesis of nanoparticles.

\subsection{Phytosynthesis of Silver Nanoparticles}

Silver nitrate was obtained from HiMedia. For understanding the impact of concentration of Silver Nitrate on synthesis of nanoparticles, reaction mixtures of $1 \mathrm{ml}$ leaf broth and $1 \mathrm{mM}$ silver nitrate solution in the ratios of 1:10, 1:20, 1:30, 1:40, 1:50 (named as S1S5) were tried in triplicates. Pure $1 \mathrm{mM}$ Silver nitrate solution and the plant extract were kept as control. All the experimental trials and controls were kept in darkness at room temperature for 48 hours. Monitoring of the changes in experimental trials was carried out from 45 minutes onwards.

After four to 6 hours, part of this reaction mixture was used for UV-vis analysis. The rest of the reaction mixtures after forty eight hours was subjected to FTIR characterization and afterwards were centrifuged at $10,000 \mathrm{rpm}$ for $10 \mathrm{mts}$ [23] and the pellet obtained was used for TEM, XRD, EDS characterization. The pellets were washed 2-3 times to remove impurities and resuspended in ultrapure water before characterization.

\subsection{UV-vis spectral and TEM analysis}

The reaction mixture was diluted to $10^{-1}$ and the reduction was observed through UV-Vis spectrophotometer (Thermoscientific) with a resolution of $1 \mathrm{~nm}$, between 200 to $1100 \mathrm{~nm}$. The TEM images (JEOL-TEM) were used to estimate the particle size. A thin film of the nanoparticles extracted from the reaction mixture as pellets was coated on to carbon coated-copper grid [24].

\subsection{XRD \& EDS}

The crystalline nature of Ag nanoparticles was further confirmed from X-ray diffraction (PANanalytical Powder XRD instrument) analysis. Nanoparticles obtained were made into a thin film and analyzed [24]. The presence of elemental silver was examined using EDS (JEOL- JSM 6390 SEM) instrument.

\subsection{FTIR studies}

These studies were carried out using Shimadzu FTIR spectrometer in attenuated total reflection mode and using an range of 4000-400 $\mathrm{cm}^{-1}$ and resolution of $4 \mathrm{~cm}^{-1}$.

\section{RESULTS \& DISCUSSION}

\subsection{Phytosynthesis of silver nanoparticles}

Change in intensity of color of the reaction mixture was taken as the preliminary evidence of nanoparticle synthesis. A color change of the reaction mixture was observed from transparent yellow to reddish brown within $45 \mathrm{mts}$ at room temperature. The appearance of reddish brown color from excitation of surface plasmon vibrations of silver nanoparticles is a clear indication of the formation of Ag nanoparticles $[25,26]$. There was no color change in any sample of the reaction mixture after 4 to $6 \mathrm{hrs}$ and the same remained stable up to seven months.

\subsection{UV-vis spectral analysis}

Among the five reaction mixtures, S1 to S5, an SPR peak is seen in all the five, but $\mathrm{S} 1$ showed a broad peak compared to that obtained in S2. Then in S3 to S5, along with SPR, peaks of silver nitrate were also obtained. Therefore, the reaction mixture S2 (1:20) was selected for further study as it showed an optimum absorbance compared to others. Fig. 1 shows the results obtained in UV-vis spectra of plant extract (a), silver nitrate (b) and S2 reaction mixture (c), taken after $6 \mathrm{~h}$ of incubation. A fairly sharp and symmetrical Surface Plasmon Resonance (SPR) peak obtained for $\mathrm{S} 2$ is indicative of small spherical particles. The broad centered peak obtained at $422 \mathrm{~nm}$ indicates slow reduction of silver ions to siver nanoparticles [27]. Appearance of silmilar peak, assigned to surface plasmon, have been documneted by Anwad
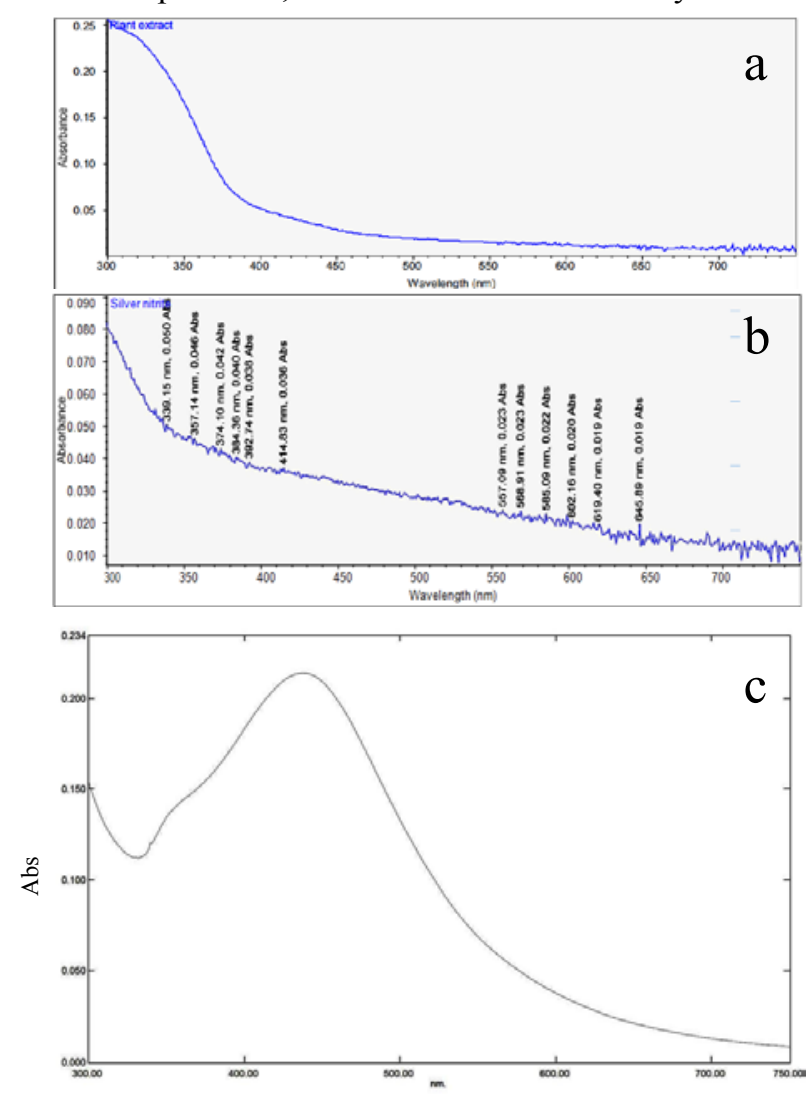

Fig. 1 V-vis Spectra of (a)plant extract,(b)silver nitrate,(c)Reaction mixture $\mathrm{S} 2$. 
http://nanobe.org
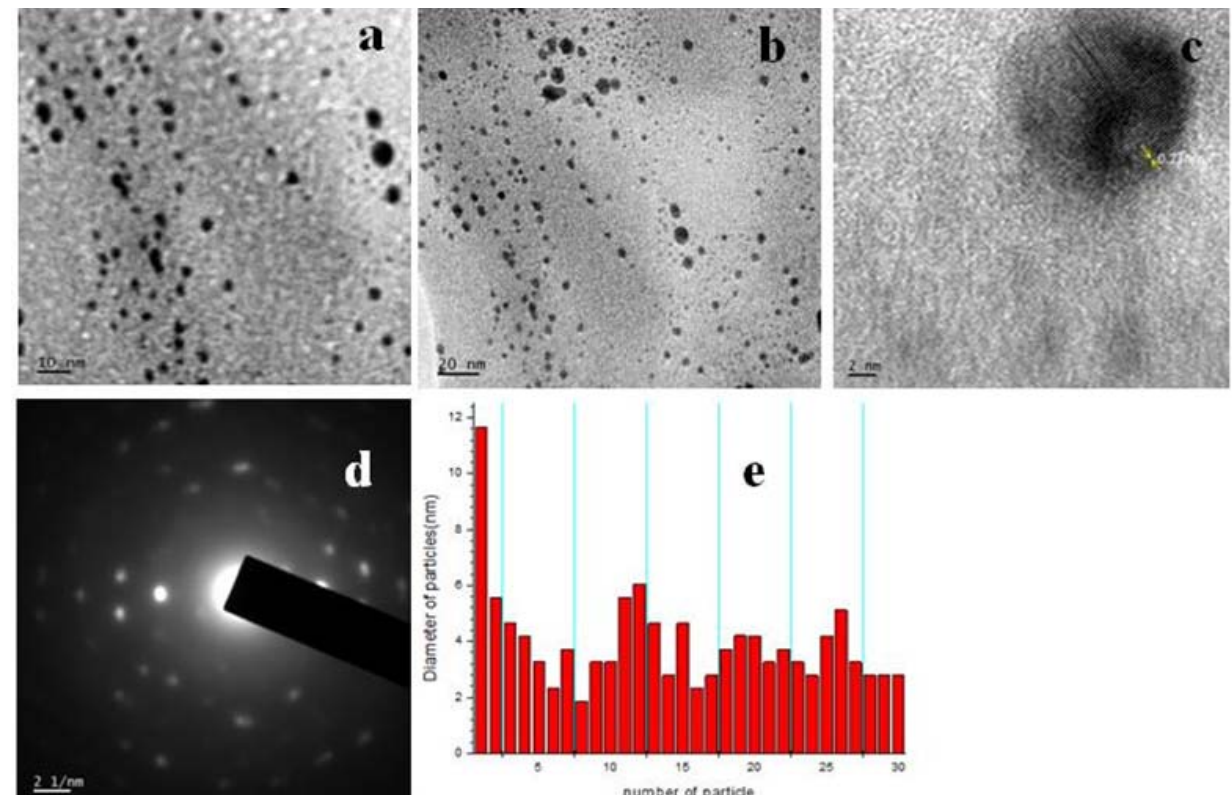

Fig. 2 TEM analysis and Particle size Histogram of Silver nanoparticles.

et al [26] at $425 \mathrm{~nm}$ and Krishnaraj et al at $420 \mathrm{~nm}$ [28]. Electrons on the metal surface undergo collective oscillation when excited by light at specific wavelength, which is known as SPR. This oscillation results in unusually strong scattering and absorption properties and the absorbance is measured using UV-Vis Spectroscopy, there by analysing the reduction of silver ions [29].

\subsection{TEM analysis}

Typical TEM images obtained with colloid S2 after $48 \mathrm{~h}$ are shown in Fig. 2 (a to d). At low magnification, large numbers of silver nanoparticles are seen. Thus the nanoparticles are quite mono dispersed and ranged in size from 3-12 $\mathrm{nm}$ with an average of $4 \mathrm{~nm}$. The morphology of nanoparticles are clearly seen at higher magnification and mainly they are spherical.

This result is in agreement with the shape of the SPR band obtained at $422 \mathrm{~nm}$, as is seen in Fig.1. In Fig. 2e the particle size distribution histogram of nano-particles obtained from HRTEM image is shown. Close examination of the TEM images showed that there is no physical contact between the particles. Moreover, a material coating is visible on the particles (Fig. 2a and 2b), which may be attributed bio organic components of the leaf broth as a covering on the nanoparticles. Shankar et al [30] have recorded similar observations on nanoparticles synthesized using geranium leaf extracts.

The TEM analysis shows the size and morphology of the synthesized nanoparticles. The high resolution TEM image of a single nanoparticle in Fig. 2c, which shows good crystallinity of the silver nanoparticles. The distance of $0.23 \mathrm{~nm}$ between the lattice planes is in agreement with the (111) lattice spacing of face centered cubic $(f c c)$ silver $(\mathrm{d} 111=0.2359 \mathrm{~nm})$. Similar results have been reported by Philip et al [27] and Dubey et al [31]. The selected area diffraction pattern (SAED) of the Ag nanoparticles is shown in Fig. 2d. Further the ring like diffraction pattern indicates that the particles are crystalline [24]. Average particle size was calculated to be $4.1 \mathrm{~nm}$ from the histogram obtained.

\subsection{XRD \&EDX Analysis}

The $\mathrm{X}$ ray diffraction confirmed the crystalline nature of silver nanoparticles. Fig 3 shows the XRD pattern obtained for silver nanoparticles synthesized using the Premna serratifolia L leaf broth. The three diffraction peaks observed in the 2 theta range $30-70$ can be indexed to the (111), (200), (220) planes of fcc silver (JCPDS file no.04-0783) [27,32]. The (200), (220) Bragg reflections are weak relative to the intense (111) reflection [33]. This feature indicates that the Nano crystals are (111) oriented as confirmed by TEM measurements [34].

Fig 4 shows the preliminary EDS measurements carried out using the JEOL-JSM 6390 SEM instrument. An intense optical absorption band peak was observed at $3 \mathrm{KeV}$, [35] which is typical of the absorption of metallic Ag Nano particles due to SPR. This further confirms the formation of silver nanoparticles by Premna serratifolia

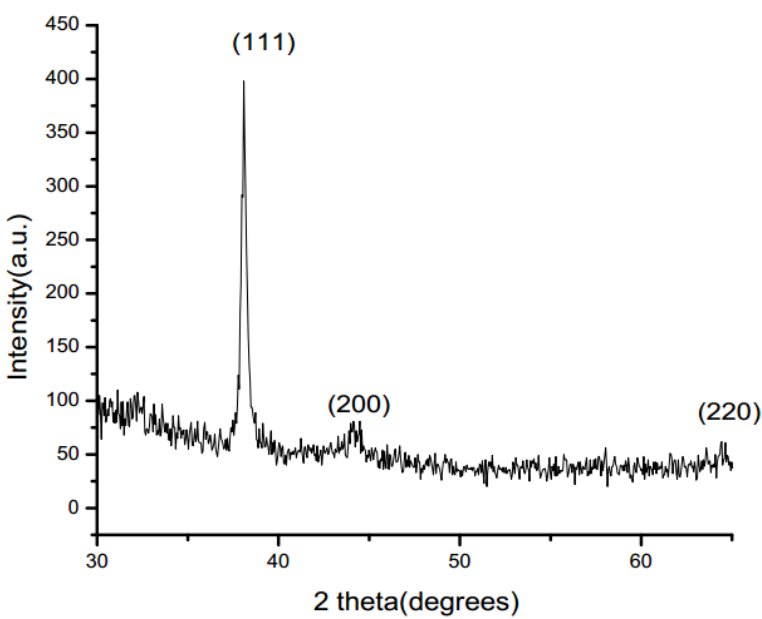

Fig. 3 XRD pattern of silver nanoparticles synthesized using Premna serratifolia leaf broth. 


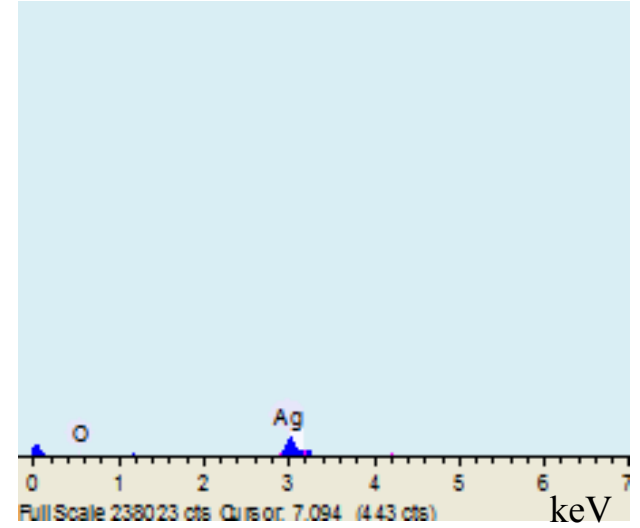

Fig. 4 Energy Dispersive X ray absorption spectroscopy.

$\mathrm{L}$ leaf broth on exposure to silver nitrate.These results are consistent with Vanaja et al [36], where silver nanoparticles have been synthesized using leaf extracts of Coleus aromaticus.

\subsection{FTIR studies}

Fig. 5 shows the FT-IR spectra of capped silver nanoparticles using Premna serratifolia L leaf broth. FTIR is done to identify the potential biomolecules responsible for reduction and capping of the bioreduced metal nanoparticles.

In Fig. 5, the IR spectrum of silver nanoparticles gives prominent bands at 3334, 3319, 3298 and 3265 $\mathrm{cm}^{-1}$ which indicates the $-\mathrm{OH}$ stretching [38] and medium peaks between 1330 and $1450 \mathrm{~cm}^{-1}$ is due to $\mathrm{OH}$ bending and both this accounts for the presence of secondary alcohols and phenols [37]. A strong IR signal at $1636 \mathrm{~cm}^{-1}$ corresponds $-\mathrm{C}=\mathrm{C}$ stretching vibration [38]. Peaks at 1456,1473 and $1489 \mathrm{~cm}^{-1}$ corresponds to the -C$\mathrm{C}$ asymmetric bending [37].

The peaks at $2980 \mathrm{~cm}^{-1}$ indicates $-\mathrm{CH}$ stretching and peaks at $1381 \mathrm{~cm}^{-1}, 943 \mathrm{~cm}^{-1}$ give $-\mathrm{CH}$ bending vibrations which may be due to $-\mathrm{CH}_{3}$ and $-\mathrm{CH}_{2}$ functional groups. At $1251 \mathrm{~cm}^{-1}$ there is a broad peak which may be due to $-\mathrm{C}-\mathrm{O}$ stretch alcohols and phenols. The series of peaks between $1250-1012 \mathrm{~cm}^{-1}$ corresponds to $-\mathrm{CN}$ stretching of aliphatic amines. The peaks between 1020 and $1091 \mathrm{~cm}^{-1}$ correspond to alcohols or phenols. The presence of amines or alcohols or phenols represents the presence of polyphenols which may be flavonoids. Similar results have been reported by Vanaja et al [36].

The study on the phytochemical analysis of Premna serratifolia L [39] shows the presence of flavanoids, terpenoids, phenolic compounds,sugars and proteins.

The vibrational bands corresponding to the bonds such as $-\mathrm{C}=\mathrm{C}-,-\mathrm{CO}$ and $-\mathrm{C}-\mathrm{O}-\mathrm{C}-$ are derived from water soluble compounds such as flavonoids, alkaloids present in the Premna serratifolia L, Thus the FTIR data indicate the presence of alcohols, aliphatic amines and phenolic compounds present in the leaf broth. It is certainly possible that these bio molecules act as reducing agents and may be responsible for mediating synthesis, capping

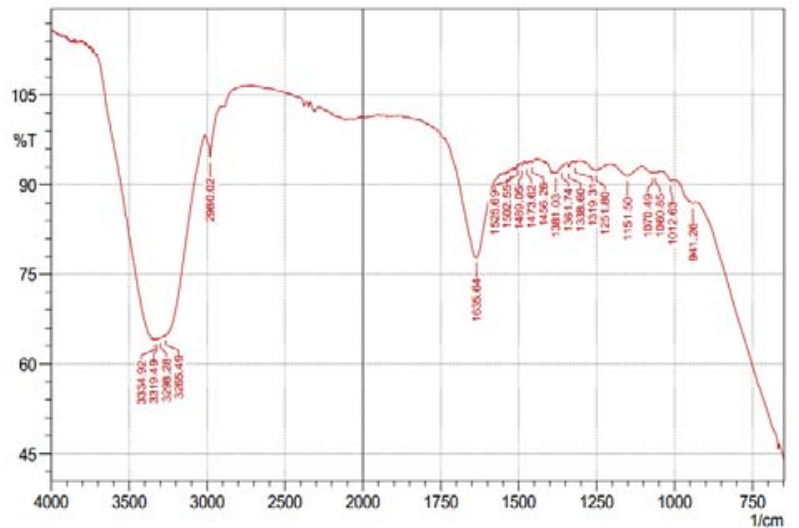

Fig. 5 FT-IR spetrum of silver nanoparticles synthesized by Premna leaves broth.

and stabilization. Especially the amine and hydroxyl groups present in the leaf extract of Premna serratifolia $\mathrm{L}$ broth might be having a positive role in the reduction and capping of silver nanoparticles.

\section{CONCLUSION}

The influence of leaf broth of Premna serratifolia L on silver nitrate have been shown and a 1:20 reaction mixture of leaf broth and $1 \mathrm{mM}$ Silver Nitrate solution was found to be the best combination compared to the other ratios analysed for nanoparticle synthesis. The size of nanoparticles produced ranged from 3-12 $\mathrm{nm}$. In general, phytosynthesized nanoparticles are considered to be environmentally benign having applications in food, agriculture, medicine and cosmetics. Therefore, the current observations of eco friendly synthesis of silver nanoparticles using leaf broth of a medicinal tree, Premna serratifolia $\mathrm{L}$ has high relevance. Especially, the newly synthesized particles are found to be quite stable and no visible changes were observed even after seven months. There were no change in the UV-vis spectroscopy values even without the addition of any stabilizing agents during this period of observaion. The reduction and stabilization of silver nanoparticles is believed to be by phenolic compounds present in the leaf broth of Premna serratifolia L. But the exact mechanism of formation and how the biomolecules interact with particles have to be further looked into. In order to make this kind of synthesis as a viable and alternative method to chemical synthesis, large scale production under controlled environmental conditions such as temperature, $\mathrm{pH}$, concentration of silver nitrate and the like should be standardized. Experiments for the same are being checked in the laboratory.

\section{Acknowledgements}

Instrumentation facilities provided by IIRBS, MGU for UV Vis spectroscopy, School of Chemical Sciences for EDS analysis, DBT MSUB facilities at School of Biosciences for FTIR studies, Centre of nanoscience at Mahatma Gandhi University for TEM are gratefully acknowledged.

\section{References}

1 Curtis A. Wilkinson C. Nanotechniques and approaches in Biotechnology. Trend. Biotechnol. 2001, 19:97-101

2 Sanvicens N. Marco M.P. Multifunctional nanoparticles-properties 
and prospects for their use in human medicine. Trend. Biotechnol. 2008, 26:425-433

3 Roy K., Mao H.Q., Huang S.K, Leong K.W. Oral gene delivery with chitosan-DNA nanoparticles generates immunologic protection in a murine model of peanut allergy. Nature Med. 1999, 5:387-391

4 Hansfield J.F., Slatkin D.N., Focella T.M., Smilowitz H.M Gold nanoparticles:a new X-RAY contrast agent. The Brit. J. Radiol. 2006, 79:248-253

5 Vaseashta A. Malinovska D.D. Nanostructured and nanoscale devices,sensors and detectors. Sci.Technol.Adv.Mater. 2005, 6: 312-318.

6 Petit C., Lixon P., Pileni M.P. In situ synthesis of silver nanocluster in AOT Reverse Micelles. J. Phys. Chem. 1993, 97: 12974-12983.

7 Keki S., Torok J., Deak G., Daroczi L., Zsuga M. Silver nanoparticles by PAMAM-assisted photochemical; reduction of $\mathrm{Ag}^{+}$. J. Colloid Interface Sci. 2000, 229:550-553.

8 Tan Y., Wang Y., Jiang L., Zhu D. Thiosalicylic Acid-Functionalized silver nanoparticles synthesized in one phase system. J. Colloid Interface Sci. 2002, 249: 336-345.

9 Nel A., Zia T., Madler L., Li N. Toxic potentials of materials at the nanolevel. Science 2006, 311:622-627.

10 Klaine J.S., Alvarez P.J.J, Btley G.E., Fernandes T.F., Handy R.D., Mahendra S., McLaughlin M.J., Lead J.R. Nanomaterials in the Environment: Behaviour,Fate,Bioavailability and Effects. Environ. Toxicol. Chem. 2008, 27:1825-1851.

11 Hall J.L. Cellular mechanisms for heavy metal detoxification and tolerance. J. Exp. Bot. 2002, 53:1-11.

12 Shankar S.S., Rai A., Ahmad A., Sastry M. Rapid synthesis of $\mathrm{Au}, \mathrm{Ag}$ and bimetallic Au core-Ag shell nanoparticles using Neem (Azadirachta indica). J. Colloid Interface Sci. 2004, 275:496-502.

13 Shankar S.S., Rai A., Ankamwar B., Singh A., Ahmad A., Sastry M. Biological synthesis of triangular gold nanoparticles. Nat. Mat. 2004, 3: 482-488.

14 Christensen L., Viekanandhan S., Misra M., Mohanty A.K. Biosynthesis of silver nanoparticles using murraya koenigii (curry leaf):An investigation on the effect of broth concentration in reduction mechanism and particles size. Adv. Mat. Lett. 2011, 6:429-434.

15 Dubey S.P, Lahtinen M., Sillanpaa M. Tansy fruit mediated greener synthesis of silver and gold nanoparticles. Process Biochem. 2010, 45:1065-1071.

16 Bar H., Bhui D.K., Sahoo G.P., Sarkar P., De S.P., Misra A. Greener synthesis of silver nanoparticles using layex of Jatropha curcas. Colloids Surf. A: Physiochem. Eng. Aspects. 2009, 339:34-139.

17 Sathishkumar M., Sneha K., Won S.W., Cho C.W., Kim S., Yun Y.S. Cinnamon zeylanicum bark extract and powder mediated green synthesis of nano-crystalline silver particles and its bactericidal activity. Colloids Surf. B: Biointerfaces. 2009,73:332-338.

18 Penn S.G., He L., Natan M.J. Nanoparticles for bioanalysis. Curr. Opin. Chem. Biol. 2003, 7: 609-615.

19 Shrivastava S., Bera T., Roy A., Singh G., Ramachandrarao P. Dash D. Characterization of enhanced antibacterial effects of novel silver nanoparticles. Nanotechnol. 2007, 18:1-9.

20 Lansdown A., Silver in health care:Antimicrobial Effects and Safety in use. Curr. Probl. Dermatol. 2008, 33:17-34.

21 Lee H.Y.,Park H.K., Lee Y.M., Kim K., Park S.B. A practical procedure for producing silver nanocoated fabric and its antibacterial evaluation for biomedical applications. Chem. Commun. 2007, 2959-2961.
22 Selvam T.N., Venkatakrishnan V., Kumar D., Elumala P. Antioxidant and Tumor Cell suppression potential of Preman serratifolia Linn leaf. Toxicol. Int. 2012, 19:31-34.

23 Ankamwar B., Damle C., Ahmad A., Sastry M. Biosynthesis of Gold and silver nanoparticles using Emblica officinalis Fruit extract, their phase transfer and transmetallation on an oragnic solution. J. Nanosci. Nanotech. 2005, 5:1665-1671.

24 Ahmad N., Sharma S., Alam M.K., Singh V.N., Shami S.F., Mehta B.R., Fatma A. Rapid synthesis of silver nanoparticles using dried medicinal plant of basil. Colloids Surf. B: Biointerfaces. 2010 , 81:81-86.

25 Sulaiman G.M., Mohammed W.H., Marzoog T.R., Amiery A., Kadhum A.A.H.K., Mohamad A.B. Green synthesis ,antimicrobial and cytotoic effects of silver nanoparticles using Eucalyptus chapmaniana leaves extract. Asian Pac J Trop Biomed. 2013, 3:58-63.

26 Awwad A.M., Salem M., Abdeen A.O. Biosynthesis of silver nanoparticles using Loquat leaf extract and its antibacterial activity. Adv. Mater. Lett. 2013, $4: 338-342$.

27 Philip D., Unni C. Extracellular biosynthesis of gold and silver nanoparticles using Krishna tulsi (Ocimum sanctum) leaf. Physica E. 2011, 43:1318-1322.

28 Krishnaraj C., Jagan E.G., Rajasekar S., Kalaichelvan P.T., Mohan N. Synthesis of silver nanoparticles using Acalypha indica leaf extracts and its antibacterial activity against water borne pathogens. Colloids and Surfaces B:Biointerfaces. 2010; 76:50-56.

29 Mulvaney P. Surface Plasmon Spectroscopy of nanosized metal particles. Langmuir 1996, 12:788-800.

30 Shankar S.S., Ahmad A., Sastry M. Geranium leaf assisted biosynthesis of silver nanoparticles. Biotechnol. Prog. 2003, 19:1627-1631

31 Dubey S.P., Lahtinen M., Silanpaa M. Tansy fruit mediated greener synthesis of silver and gold nanoparticles. Colloids Surf. A: Physiochem. Eng. Aspects. 2010, 364:34

32 Huang J., Li Q., Sun D., Lu Y., Su Y., Yang X., Wang H., Wang Y., Shao W., He N., Hong J., Chen C. Biosynthesis of silver and gold nanoparticles by novel sundried Cinnamomum camphora leaf. Nanotechnol. 2007, 18:105104.

33 Ankamwar B., Chaudhary M., Sastry M. Gold nanotriangles biologically synthesized using tamarind leaf extract and potential application in vapor sensing. Synth. React. Inorg. Met-Org. Nan. 2005, 35:19-25.

34 Kannan P., John S.A. Synthesis of mercaptothiadiazole-functionalized gold nanoparticles and their self-assembly on AU substrates. Nanotechnol. 2008, 19:085602.

35 Magudapathy P., Gangopadhyay P., Panigrahi B.K., Nair K.G.M., Dhara S. Electrical transport studies of Ag nanoclusters embedded in glass matrix. Physics B. 2001, 299:142-146.

36 Vanaja M., Annadurai G. Coleus aromaticus leaf extract mediated synthesis of silver nanoparticles and its antibacterial activity. Appl. Nanosci. 2013, 3:217-223.

37 Agarwal S.S., Paridhavi M. Herbal Drug Technology, University Press, 2007.

38 Coates J. Encyclopedia of Analytical Chemistry.John Wiley \& Sons Ltd,Chichester, 2000:10815-10837.

39 Singh C.R., Nelson R., Krishnan P.M., Pargavi B. Identification of volatile constituents from Premna serratifolia L.through GC-MS. Int. J. Pharm.Tech .Res. 2011, 3:1050-1058.

Copyright:(c) 2013 S. Soman and J. Ray. This is an open-access article distributed under the terms of the Creative Commons Attribution License, which permits unrestricted use, distribution, and reproduction in any medium, provided the original author and source are credited. 